\title{
Severe forms of Baraitser-Winter syndrome are caused by ACTB mutations rather than ACTG1 mutations
}

\author{
N Di Donato ${ }^{\star, 1,7}$, A Rump ${ }^{1,7}$, R Koenig ${ }^{2}$, V M Der Kaloustian ${ }^{3}$, F Halal ${ }^{4}$, K Sonntag ${ }^{1}$, C Krause ${ }^{1}$, \\ K Hackmann ${ }^{1}$, G Hahn ${ }^{5}$, E Schrock ${ }^{1}$ and A Verloes ${ }^{6}$
}

ACTB and ACTG1 mutations have recently been reported to cause Baraitser-Winter syndrome (BRWS) - a rare condition characterized by ptosis, colobomata, neuronal migration disorder, distinct facial anomalies and intellectual disability. One of the patients carrying an ACTB mutation was previously diagnosed with Fryns-Aftimos syndrome (FAS), which is a rare and severe, multiple congenital anomaly (MCA) syndrome whose symptoms partially overlap with that of BRWS. However, several patients with Fryns-Aftimos were considered not to fit into the ACTB and ACTG1 spectrum because of their severe impairment and additional malformations. We report on three patients who had been diagnosed with FAS. All three patients carry a mutation in the $A C T B$ gene. On the basis of the $A C T B$ mutations and analysis of the clinical findings, we reclassify the diagnosis of these patients as severe BRWS. We suggest that mutations in ACTB cause a distinctly more severe phenotype than ACTG1 mutations, despite the structural similarity of beta- and gamma-actins and their overlapping expression pattern. We expand the spectrum of BRWS and confirm that FAS is not a separate entity but an early and severe manifestation of BRWS. European Journal of Human Genetics (2014) 22, 179-183; doi:10.1038/ejhg.2013.130; published online 12 June 2013

Keywords: Baraitser-Winter syndrome; Fryns-Aftimos syndrome; pachygyria; intellectual disability; cytoplasmic actins

\section{INTRODUCTION}

Baraitser-Winter syndrome (BRWS) is a rare developmental disorder characterized by congenital ptosis, ocular colobomata, anterior neuronal migration disorder (pachygyria, lissencephaly), distinct facial anomalies and intellectual disability (ID). As BRWS is caused by mutations in two different genes (ACTB and ACTG1), ${ }^{1}$ OMIM identifies two types of BRWS (OMIM 243310 and 614583), although the phenotypes linked to both genotypes are largely indistinguishable.

Fryns-Aftimos syndrome (FAS; OMIM 606155) is a rare condition with multiple anomalies and severe ID. The main clinical features are facial dysmorphism, anterior neuronal migration disorder (pachygyria) and cerebral atrophy, short webbed neck and limited extension of the large joints with pterygia. Facial features are striking: arched eyebrows; proptosis, hypertelorism; downslanting palpebral fissures; broad nasal bridge; macrostomia and dysplastic, low-set ears. Two patients were reported with duplicated halluces. ${ }^{2,3}$ One of the original patients reported by Fryns and Aftimos ${ }^{4}$ was recently shown to carry an $A C T B$ mutation. ${ }^{1}$

There is a significant clinical overlap between BRWS and FAS, ${ }^{5}$ although the conditions were initially reported as two independent entities. After the discovery of an ACTB mutation in a patient originally reported by Fryns and Aftimos, ${ }^{4}$ Riviere et al ${ }^{1}$ suggested that BRWS and FAS are actually one and the same condition. They proposed that the distinctive clinical phenotypes are caused by age differences, where coarser facial features and more restricted joint movements are associated with advanced age. ${ }^{1}$

\section{CLINICAL REPORTS}

Patient 1 (Figure 1). The patient, a female, was born as a second child of healthy non-consanguineous parents - a 34-year-old mother and 35-year-old father. The family history was unremarkable.

As early as 22 weeks of gestation (GW), hydrops fetalis with severe polyhydramnios, abnormal head shape and hypertelorism were observed. The girl was born in the 39th GW weighing $2900 \mathrm{~g}(-1.1$ $\mathrm{SD})$ and measuring $46 \mathrm{~cm}$ in height $(-2.3 \mathrm{SD}$ ). She had pansynostosis (requiring surgery during the first year of life), neuronal migration disorder (frontal pachygyria, subependymal neuronal heterotopias), hypoplastic corpus callosum, bilateral eye coloboma (irido-fundal on the right and fundal on the left eye), intestinal malrotation, ectopic kidneys, diastasis recti, duplicated halluces, short webbed neck, congenital webbing at axillae and elbows and restricted extension of the shoulders, elbows and knees, with severe muscular hypoplasia of the shoulder girdle muscles. Facial dysmorphism included high arched eyebrows, proptosis, hypertelorism, downslanted palpebral fissures, broad nasal bridge, broad nasal tip and columella, anteverted nostrils, macrostomia, very high and narrow palate, crowded teeth, low-set, long, dysplastic ears and low posterior hairline.

She started to walk at the age of 3 years. The seizures started at the same age (multifocal epilepsy) and were poorly controlled. Her hearing was unaffected; however, she did not speak and had severe ID. A slow decline in motor function was noted from the age of 17 .

\footnotetext{
${ }^{1}$ Institute for Clinical Genetics, Faculty of Medicine Carl Gustav Carus TU Dresden, Dresden, Germany; ${ }^{2}$ Institute of Human Genetics, Johann Wolfgang Goethe University Hospital, Frankfurt/Main, Germany; ${ }^{3}$ Departments of Pediatrics and Human Genetics, McGill University, Montreal, PQ, Canada; ${ }^{4}$ Department of Medical Genetics, Montreal Children's Hospital, McGill University Health Centre, Montreal, PQ, Canada; ${ }^{5}$ Institute of Diagnostic Radiology, Department of Pediatric Radiology, Faculty of Medicine Carl Gustav Carus TU Dresden, Dresden, Germany; ${ }^{6}$ Department of Genetics, Robert-Debré Hospital, Paris, France

${ }^{7}$ These authors contributed equally to the work.

*Correspondence: Dr Nataliya Di Donato, Institute for Clinical Genetics, Faculty of Medicine Carl Gustav Carus TU Dresden, Fetscherstrasse 74, 01309 Dresden, Germany. Tel: +49 351458 5137; Fax: +49 351458 4316; E-mail: nataliya.didonato@uniklinikum-dresden.de

Received 28 February 2013; revised 13 May 2013; accepted 15 May 2013; published online 12 June 2013
} 

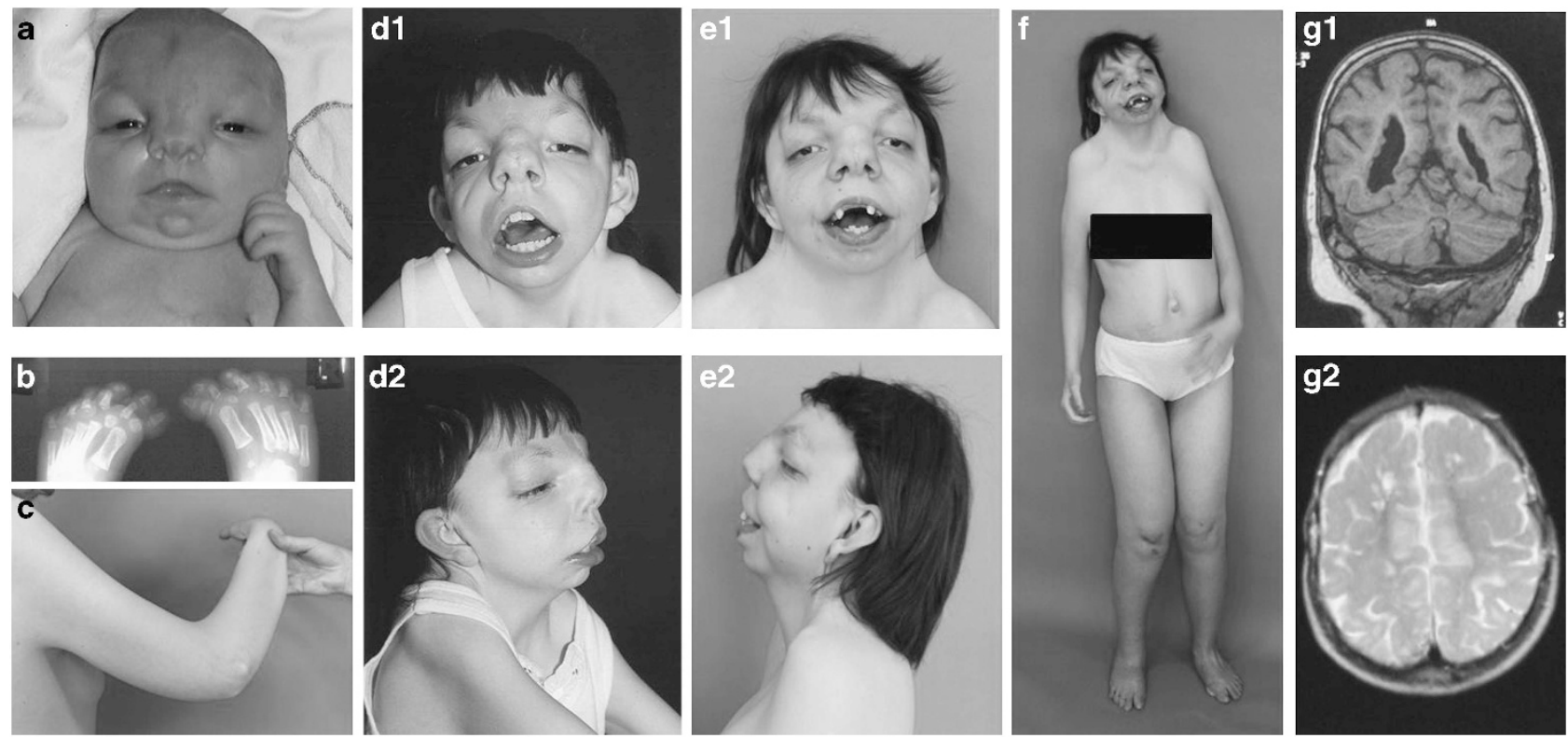

Figure 1 Patient 1, phenotype follow-up. (a) Patient at the age of 6 months; (b) X-ray of the feet at the age of 3 years, note double halluces; (c) webbing at axilla and elbows; (d) patient at the age of 8 years; (d1) anterior and (d2) lateral view; (e-f) patient at the age of 20 years; (e1) anterior and (e2) lateral view; (g) brain MRI scans of patient 1 at the age of 10 years; (g1) T1-weighted coronal section shows bilateral subependymal heterotopia; (g2) T2-weigted transversal section shows bilateral frontal pachygyria.
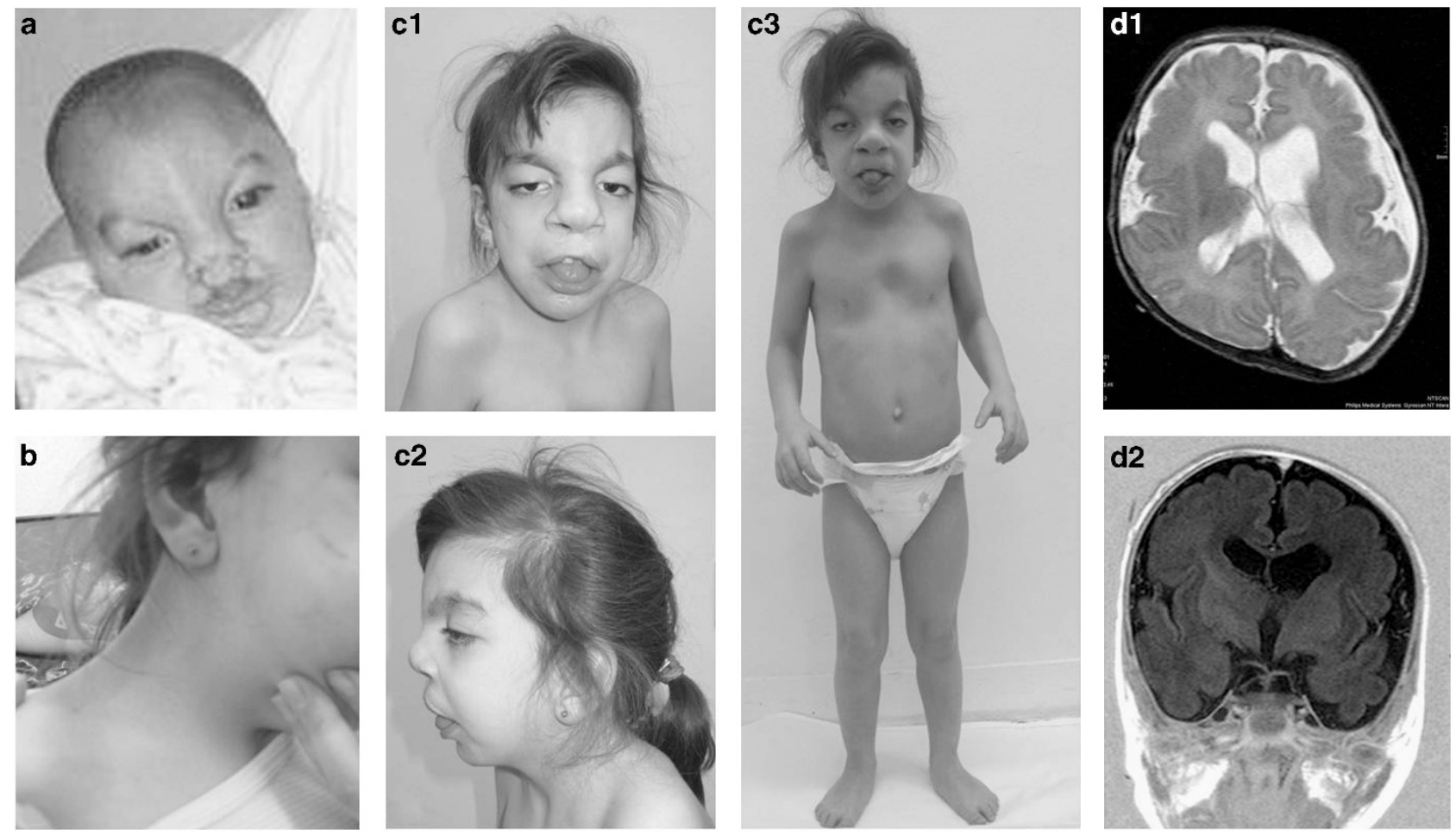

Figure 2 Patient 2, phenotype follow-up. (a) Patient during the first year of life, note bilateral cleft lip; (b) nuchal webbing; (c) patient at the age of 8 years; (c1) face anterior view; (c2) face lateral view; (c3) whole body image; (d) brain MRI scans of patient 2 at the age of 3 months; (d1) T2-weighted transversal section shows bilateral pachygyria; (d2) T1-weighted IR coronal section shows hypoplastic corpus callosum and dilatation of the lateral and third ventricles.

At the last follow-up (20 years), her height was $160 \mathrm{~cm}$ ( $-0.8 \mathrm{SD})$, weight was $55 \mathrm{~kg}$ (1 SD, BMI $\left.21.5 \mathrm{~kg} / \mathrm{m}^{2}\right)$ and OFC was $52.4 \mathrm{~cm}(1.4 \mathrm{SD})$. The menarche occurred at the age of 19 years, followed by the repeated spotting that was treated by depot medroxyprogesterone acetate injections.
Patient 2 (Figure 2). The patient was born as a second child of a healthy 31-year-old woman but was the only child of her 44-year-old father. The family history was unremarkable.

Prenatally, she presented with severe polyhydramnios and hydrops fetalis that required a cesarean section at the 32nd GW. 


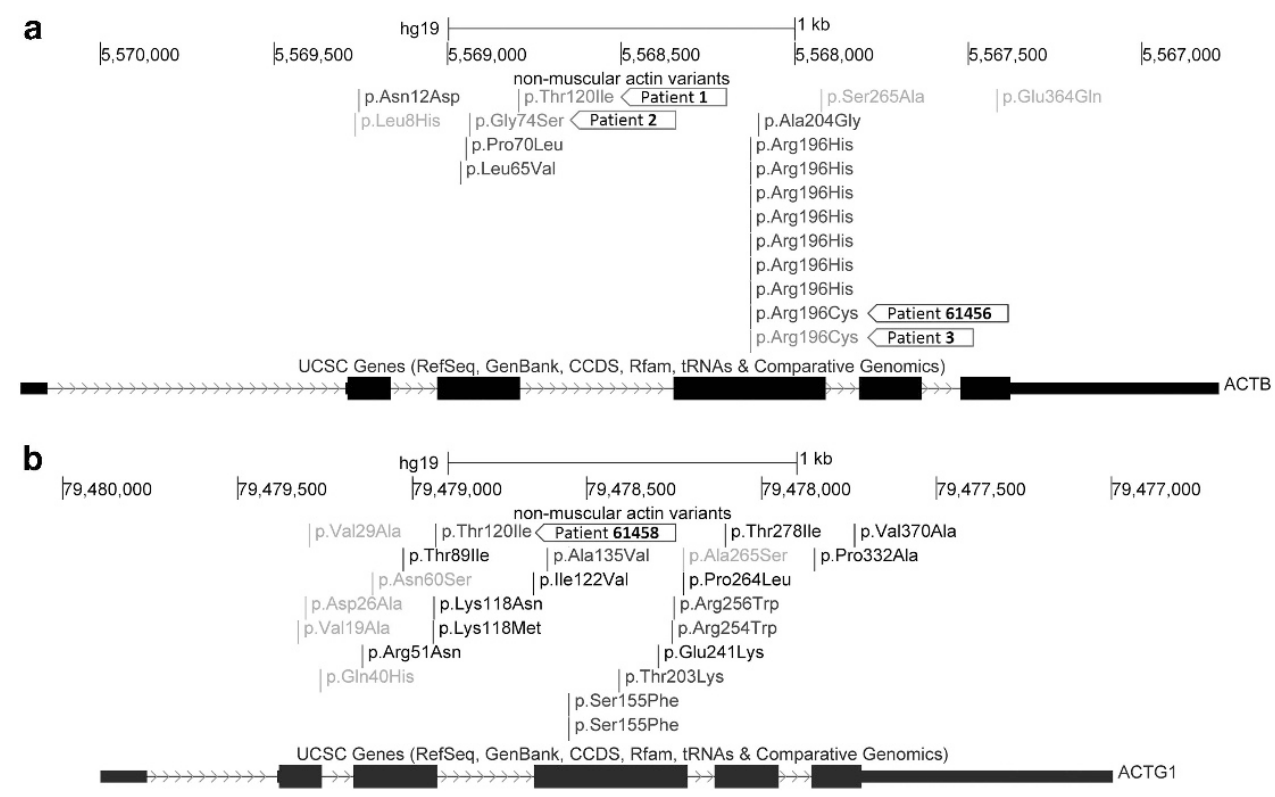

Figure 3 Mutation distribution in ACTB and ACTG1. Transcripts and sequence variants of (a) ACTB (chr7:5,566,501-5,570,500) and (b) ACTG1 (chr17:79,476,401-79,480,400). Both genes are shown in the UCSC hg19 assembly and drawn at the same scale. The different isoforms of each gene are represented by black/blue vertical lines, in which solid boxes represent exons and the thin areas with arrows illustrate introns and direction of transcription. Missense mutations are represented by thin vertical ticks in different colors: black, hearing loss; blue, BRWS with moderate phenotype; red, BRWS with severe phenotype; green, variants from $\sim 6000$ healthy individuals, as listed in the exome variant server. Red arrows indicate mutations in patients $1-3$. Blue arrows indicate mutations in patients 61456 and 61458 (Rivière et al ${ }^{1}$ ).

Birth height was $42 \mathrm{~cm}(-0.18 \mathrm{SD})$, weight $2160 \mathrm{~g}(1.01 \mathrm{SD})$ and OFC $31 \mathrm{~cm}(0.63 \mathrm{SD})$.

Heart defects (ventricular septal defect and patent ductus arteriosus) and a bilateral cleft lip with cleft palate were present at birth and required several operations. The patient had moderate-to-severe ID with no speech. She started to walk at the age of 4 years. The seizures began in the first few weeks after birth and required continuous medication. The hearing as well as ophthalmological status was normal.

At the age of 8 , she presented with anterior pachygyria, trigonocephaly, a short and webbed neck and a narrow thorax with the hypoplasia of the thoracic and shoulder girdle muscles and funnel chest deformity. Her facial anomalies included high arched eyebrows, hypertelorism, downslanted palpebral fissures, a broad nasal bridge, a broad nasal tip and columella, anteverted nostrils, macrostomia and a low posterior hairline. She was $108 \mathrm{~cm}$ tall ( $-3 \mathrm{SD}$ ), weighed $18.5 \mathrm{~kg}$ (BMI $\left.15.86 \mathrm{~kg} / \mathrm{m}^{2}\right)$ and had an OFC of $49 \mathrm{~cm}(-2 \mathrm{SD})$.

Patient 3 was previously described by Der Kaloustian et al. ${ }^{3}$ The male patient was observed at the age of 16 years and showed multiple craniofacial anomalies (trigonocephaly; high arched eyebrows; ptosis; hypertelorism; a broad nasal bridge; a broad nasal tip and columella; anteverted nostrils; macrostomia; very high and narrow palate; low-set, long, dysplastic ears; low posterior hairline and a webbed neck), frontal pachygyria, congenital pterygia at the axillae and elbows, duplicated halluces, genital anomalies, bilateral hydronephrosis and a duplication of the right collecting system. The patient had moderate ID and severely impaired speech. At his 20s, he developed severe respiratory failure and died after the administration of Triatec-30 - a combination of codeine and acetaminophen. The genetic variant of CYP2D6 (ultrarapid metabolizers) was assumed to be the reason for the adverse drug reaction after codeine administration.

\section{INVESTIGATIONS AND RESULTS}

In patients 1 and 2, high-resolution array-CGH analysis - using the Agilent $2 \times 400 \mathrm{~K}$ microarray chips (Agilent Technologies, Santa Clara, CA, USA) - revealed only known benign CNVs listed in the Database of Genomic Variants. Cytogenetic analysis showed unremarkable 46,XX karyotypes.

\section{Sanger sequencing of the $A C T B$ gene}

Patient 1 carried the heterozygous missense mutation NM_001101.3:c.359C > T (p.Thr120Ile). This mutation was absent in her healthy mother and brother; the father (reported to be healthy) was not available for analysis.

Patient 2 carried the heterozygous missense mutation NM_001101.3:c.220 G>A (p.Gly74Ser). This mutation was excluded in the healthy mother, while the father (reported to be healthy) also was not available for analysis.

Patient 3 had a de novo heterozygous missense mutation NM_001101.3:c.586C > T (p.Arg196Cys).

\section{Sanger sequencing of $A C T G 1$}

Sequencing of ACTG1 did not reveal any mutation in these three patients, but showed known SNPs (rs9910792, rs1139405) in patient 1 and 3, respectively. Primers for both genes were designed using the 'ExonPrimer'-tool (Helmholtz Center, Munich, Germany; http:// ihg.gsf.de/ihg/ExonPrimer.html) in the UCSC browser and are listed in Supplementary Table 1.

\section{DISCUSSION}

\section{BRWS and FAS represent the same clinical entity}

Patient 1 presented with bilateral coloboma and pachygyria hallmarks of BRWS - and with duplicated halluces, multiple pterygia, joint contractures and unusual body habitus, which fit the clinical frame of FAS patients. ${ }^{3,6,7}$ Absence of ocular coloboma and the 
Table 1 Clinical features of the reported ACTB/ACTG1 mutation-positive patients (modified after Rivière et al ${ }^{1}$ )

\begin{tabular}{|c|c|c|c|c|c|c|}
\hline Patient ID & $\begin{array}{c}\text { ACTB } \\
\text { patients }\end{array}$ & $\begin{array}{l}\text { ACTG1 } \\
\text { patients }\end{array}$ & 61458 & Patient 1 & Patient 2 & Patient 3 \\
\hline $\begin{array}{l}\text { Gender } \\
\text { Mutation }\end{array}$ & $\begin{array}{l}6 \mathrm{~F} / 4 \mathrm{M} \\
10\end{array}$ & $\begin{array}{l}4 F / 4 M \\
8\end{array}$ & $\begin{array}{c}\mathrm{F} \\
\text { ACTG1 p.Thr120lle }\end{array}$ & ACTB p.Thr120lle & $\begin{array}{c}\mathrm{F} \\
A C T B \\
\text { p.Gly74Ser }\end{array}$ & $\begin{array}{c}\mathrm{M} \\
\text { ACTB p.Arg196Cys }\end{array}$ \\
\hline $\begin{array}{l}\text { Prenatal } \\
\text { manifestation }\end{array}$ & NA & NA & - & + (Hydrops, hypertelorism) & + (Hydrops) & - \\
\hline Short stature at birth & NA & NA & - & + & - & - \\
\hline $\begin{array}{l}\text { (last follow-up) } \\
\text { Microcephaly } \\
\text { (last follow-up) }\end{array}$ & $6 / 9$ & $4 / 7$ & $-(26 y)$ & $-(20 y)$ & $+(8 \mathrm{y})$ & $+(16 \mathrm{y})$ \\
\hline $\begin{array}{l}\text { Neurological } \\
\text { ID }\end{array}$ & $\begin{array}{l}9 / 9(2 \\
\text { severe) }\end{array}$ & $5 / 5$ & Mild & Severe & Severe & Severe \\
\hline $\begin{array}{l}\text { Speech } \\
\text { Hearing loss } \\
\text { Seizures }\end{array}$ & $\begin{array}{l}\text { NA } \\
4 / 8 \\
9 / 9\end{array}$ & $\begin{array}{l}N A \\
5 / 6 \\
7 / 8\end{array}$ & $\begin{array}{c}\text { Present } \\
+ \\
+(\text { Poorly controlled })\end{array}$ & $\begin{array}{c}\text { Absent } \\
- \\
+(\text { Poorly controlled })\end{array}$ & $\begin{array}{c}\text { Absent } \\
- \\
+ \text { (Controlled) }\end{array}$ & $\begin{array}{c}\text { Reduced } \\
+ \\
+ \text { (Controlled) }\end{array}$ \\
\hline $\begin{array}{l}\text { Malformations } \\
\text { Eye coloboma } \\
\text { Neuronal migration } \\
\text { disorder }\end{array}$ & $\begin{array}{l}6 / 10 \\
8 / 8\end{array}$ & $\begin{array}{l}5 / 7 \\
7 / 7\end{array}$ & + Pachygyria & + Pachygyria, heterotopia & + Pachygyria & + Pachygyria \\
\hline $\begin{array}{l}\text { Congenital pterygia } \\
\text { Additional } \\
\text { malformations }\end{array}$ & $\begin{array}{l}\text { NA } \\
\text { NS }\end{array}$ & $\begin{array}{l}\text { NA } \\
\text { NS ( } 1 \text { cleft } \\
\text { lip/palate) }\end{array}$ & $\begin{array}{l}\text { Acquired limited } \\
\text { extension of the large joints, } \\
\text { that worsened with time }\end{array}$ & $\begin{array}{l}+ \\
\text { Double halluces, intestinal } \\
\text { malrotation, ectopic kidneys, } \\
\text { diastasis recti, congenital limited } \\
\text { extension of the large joints }\end{array}$ & $\begin{array}{l}+ \\
\text { Cleft lip/ } \\
\text { palate, VSD, } \\
\text { PDA }\end{array}$ & $\begin{array}{l}+ \\
\text { Double halluces, scoliosis, } \\
\text { hydronephrosis, duplication of } \\
\text { the right collecting system }\end{array}$ \\
\hline
\end{tabular}

Abbreviations: F, female; ID, intellectual disability; M, male; NA, data not available; NS, not specified; PDA, patent ductus artesiosus; VSD, ventricular septal defect; y, years.

presence of duplicated halluces and pterygia with knee and elbow contractures were initially regarded as sufficient by Rivière et al ${ }^{1}$ to clinically exclude BRWS in two patients previously assigned to FAS. One of the 'excluded' patients is patient 3 , in whom we could identify a recurrent $A C T B$ mutation c.586C $>\mathrm{T}$ (p.Arg196Cys) that was also seen in patient 61456 in the cohort of Rivière et al. ${ }^{1}$

The overlap of BRWS and FAS-associated clinical features in patient 1 and the occurrence of $A C T B$ mutations in the three reported patients clearly demonstrate that BRWS and FAS represent various degrees of severity of the same clinical entity. We propose that all reported FAS patients should be reclassified as patients with severe BRWS.

\section{Expansion of the clinical spectrum of $A C T B$-associated BRWS}

The malformation spectrum of BRWS should be extended to include congenital pterygia, abdominal anomalies and preaxial polydactyly. BRWS may manifest prenatally with nuchal edema or even hydrops fetalis.

It remains unknown, why and how an $A C T B$ mutation leads to abnormal limb development. Although $A C T B$ is considered to be a crucial developmental gene involved in cell migration, ${ }^{8}$ it was neither studied during digit patterning nor shown to directly interact with crucial signaling pathways of the limb bud.

Congenital pterygia and muscle hypoplasia, as well as hydrops, point to prenatal hypokinesia. This was not seen in the original series of patients. ${ }^{1} \beta$-actin is a cytoplasmic actin isoform with ubiquitous expression and one of the components of the actin filaments (F-actin). New biochemical evidence suggest that F-actin properties may vary according to the mix of isoforms in the filament, and the change of one isoform causes the compensatory upregulation of the others. ${ }^{9}$ Certain ACTB mutations might initiate early changes in the filaments of the skeletal muscles, whereas effects of the other mutations may be compensated by the overexpression of the other actin isoforms.

Patient 2 presented with a bilateral cleft lip and cleft palate. Although not a typical feature of BRWS, cleft lip/palate has already been reported in connection with $A C T B$ point mutations ${ }^{10}$ and deletions of the whole gene. ${ }^{1}$ Cleft lip/palate was also seen in a BRWS patient carrying an ACTG1 mutation (58431 in Rivière et al, ${ }^{1}$ ) and thus should be included in the clinical presentation of BRWS spectrum. The mechanisms of the cleft formations also remain to be clarified.

\section{$A C T B$ mutations cause a more severe phenotype than mutations in ACTG1}

All patients presented here carry missense mutations in the ACTB gene (Figure 3). Two of these mutations (p.Gly74Ser and p.Thr120Ile) have not been reported before, either in patients or in variant databases like dbSNP or the NHLBI ESP Exome Variant Server. The finding of additional missense mutations in BRWS patients substantiates the assumption of Rivière et al that BRWS is caused by a dominant-negative effect or by gain-of-function rather than by haploinsufficiency. 
The ACTB mutation NM_001101.3:c.359C $>\mathrm{T}$ in patient 1 is an analog to the ACTG1 mutation NM_001614.1:c.359C $>\mathrm{T}$ in patient 61458, in the report of Rivière et al ${ }^{1}$ (Table 1). Patient 61458 exhibited the typical features of BRWS (trigonocephaly, hypertelorism, high arched eyebrows, congenital ptosis, pterygium colli, limited extension of the large joints that worsened over time and frontal pachygyria). At the same time, this patient showed significantly milder symptoms than patient 1: she developed active speech, her ID was estimated as mild and she did not have any other congenital malformation except pachygyria.

Patient 1 and patient 61458 of Rivière et al ${ }^{1}$ carry a mutation that affects the same position in $\beta$ - and $\gamma$-actin. ${ }^{11}$ ACTG and ACTB1 have identical exon structures and their gene products vary by only four amino acids. Despite their similarity and their overlapping expression pattern, these proteins differ significantly in their subcellular localization, ${ }^{12}$ post-translational modifications (arginylation of the $\beta$-actin, but not $\gamma$-actin ${ }^{13}$ ) and consequently have no completely redundant function, ${ }^{14}$ but a partially overlapping one. Comparing the phenotypic consequences of the c.359C $>\mathrm{T}$ mutation in $A C T B$ with the consequences of the analogous mutation in ACTG1, we observed that $A C T B$ mutations can cause a more severe phenotype than ACTG1 mutations.

This fact is concordant with the observation that $\beta$-actin-knockout mice die during early embryonic development, ${ }^{8}$ whereas $\gamma$-actinknockouts are viable. ${ }^{15}$ However, a larger patient cohort with mutations in both genes is required for the further analysis of the difference between the effects of the mutations in ACTB and ACTG1.

Further functional analysis of the human $A C T B$ and ACTG1 mutations will contribute to the elucidation of the cellular functions of $\beta$ - and $\gamma$-actins. Future data should settle the matter of whether the severe phenotypic effect of $A C T B$ mutations in the reported patients is only due to the functional role of $\beta$-actin, or by the presence of additional mutations in other genes (so called multiple hits).

Variable expressivity of $A C T B$ mutation c.586C $>\mathrm{T}$ (p.Arg196Cys) The ACTB mutation c.586C > T (p.Arg196Cys) observed in patient 3 was previously reported by Rivière et $a^{1}$ in patient 61456 . With no additional malformations, patient 61456 had a considerably milder phenotype than patient 3. We expect that as yet unknown genetic modifiers might have an impact on the clinical severity and on the malformation spectrum. The most obvious modifier candidate, ACTG1, did not show an additional mutation in patient 3 and, therefore was not likely to contribute to the severity of the disease in this individual.

Taken together, BRWS may present as a congenital MCA syndrome (formerly known as FAS) with prenatal manifestation and a severe phenotype when caused by mutations in $A C T B$ rather than in ACTG1.

\section{CONFLICT OF INTEREST}

The authors declare no conflict of interest.

\section{ACKNOWLEDGEMENTS}

We thank the families for their enthusiastic cooperation.

1 Riviere JB, van Bon BW, Hoischen A et al: De novo mutations in the actin genes ACTB and ACTG1 cause Baraitser-Winter syndrome. Nat Genet 2012; 44: S1-S2.

2 Guion-Almeida ML, Richieri-Costa A: Acrocallosal syndrome: report of a Brazilian girl. Am J Med Genet 1992; 43: 938-941.

3 Der Kaloustian VM, Pelletier M, Costa T, Blackston DR, Oudjhane K: A new syndrome with craniofacial and skeletal dysmorphisms and developmental delay. Clin Dysmorphol 2001; 10: 87-93.

4 Fryns JP, Aftimos S: New MR/MCA syndrome with distinct facial appearance and general habitus, broad and webbed neck, hypoplastic inverted nipples, epilepsy, and pachygyria of the frontal lobes. J Med Genet 2000; 37: 460-462.

5 Winter RM: Cerebro-fronto-facial syndrome: three types? Clin Dysmorphol 2001; 10: 79-80.

6 Guion-Almeida ML, Richieri-Costa A: Frontonasal dysplasia, macroblepharon, eyelid colobomas, ear anomalies, macrostomia, mental retardation and CNS structural anomalies: defining the phenotype. Clin Dysmorphol 2001; 10: 81-86.

7 Forzano F, Faravelli F, Di Rocco M: Cerebro-fronto-facial syndrome: report of a further case. Clin Dysmorphol 2004; 13: 121-122.

8 Bunnell TM, Burbach BJ, Shimizu Y, Ervasti JM: beta-Actin specifically controls cell growth, migration, and the G-actin pool. Mol Biol Cell 2011; 22: 4047-4058.

9 Perrin BJ, Ervasti JM: The actin gene family: function follows isoform. Cytoskeleton (Hoboken) 2010; 67: 630-634.

10 Procaccio V, Salazar G, Ono S et al: A mutation of beta -actin that alters depolymerization dynamics is associated with autosomal dominant developmental malformations, deafness, and dystonia. Am J Hum Genet 2006; 78: 947-960.

11 Vandekerckhove J, Weber K: At least six different actins are expressed in a higher mammal: an analysis based on the amino acid sequence of the amino-terminal tryptic peptide. J Mol Biol 1978; 126: 783-802.

12 Dugina V, Zwaenepoel I, Gabbiani G, Clement S, Chaponnier C: Beta and gammacytoplasmic actins display distinct distribution and functional diversity. J Cell Sci 2009; 122: 2980-2988.

13 Karakozova M, Kozak M, Wong CC et al: Arginylation of beta-actin regulates actin cytoskeleton and cell motility. Science 2006; 313: 192-196.

14 Bulinski JC: Cell biology. Actin discrimination. Science 2006; 313: 180-181.

15 Belyantseva IA, Perrin BJ, Sonnemann KJ et al: Gamma-actin is required for cytoskeletal maintenance but not development. Proc Natl Acad Sci USA 2009; 106: 9703-9708.

Supplementary Information accompanies this paper on European Journal of Human Genetics website (http://www.nature.com/ejhg) 